\title{
Future in neuromedicine: Nanotechnology
}

Sir,

The concept of nanomedicine is a new and exciting topic. Its application in neurology is a promising field for research. Use of nanoparticles in neuromedicine undoubtedly will open up a new horizon. The aim of this letter is to highlight some recent data about the use of nanotechnology in neuromedicine.

Recently, an animal study has shown an encouraging result in multiple sclerosis as well as autoimmune encephalitis by administration of nanodroplet formulation of pomegranate seed oil. ${ }^{[1]}$

In the case of refractory epilepsy, optimum drug delivery to the brain is an ongoing battle. Tryptophan-derived nanoparticles showed promising outcome in drug delivery in refractory seizure disorder patients. ${ }^{[2]}$ Nanoparticles are postulated to target myeloid cells in epileptogenic brain tissue of rats. Presurgical and intrasurgical localization of epileptic foci can be done by these particles. This technique will be helpful for future treatment of epilepsy. ${ }^{[3]}$

Multimer detection system causes differentiation of prion multimers through their multimeric expression of epitopes. Probably, it is going to be a great achievement to diagnose prion-associated diseases using nanotechnology. ${ }^{[4]}$
New nanoparticles have been found that can enable remote-controlled magnetic guiding for stem cell homing. The method may result in positive end point for treatment of many diseases including stroke. ${ }^{[5]}$

The existence of the blood-brain barrier causes hindrance for targeted drug delivery within brain tissue. "Autocatalytic" approach has been proposed to combat this problem. Few nanoparticles enter into the brain through the process of transcytosis or the gaps in blood brain barrier. The nanoparticles release some blood brain barrier modulators, which results in more nanoparticles entry. This technique has a potential role in treatment as well as imaging of brain tumor. ${ }^{[6]}$

Recently, nanoparticles help increase the permeability of blood brain barrier by proper delivery of lexiscan to central nervous system. The technique autocatalytically augments the targeting delivery of chlorotoxin-anchored nanoparticles. Nogo-66 receptor antagonist peptide NEP1-40 loaded nanoparticles have been shown to cause reduction of infarct volume. ${ }^{[7]}$

Hence, these nanotechnologies will reduce the problem of drug delivery due to the blood-brain barrier. In the case of neurodegenerative disorders also improved drug delivery will bring a significant improvement in the disease course. ${ }^{[8]}$ 
Gadolinium-based nanoparticles in combination with radiation therapy showed increased tumor cells death in animals with multiple brain melanoma metastasis. ${ }^{[9]}$

It is interesting that nanotechnology is emerging as a promising modality for the treatment of brain cancer.

Iron nanoparticles are used for labeling human neural stem cells. This technique will help track the localization as well as the survival of the stem cells. In patients with Parkinson's disease, magnetic resonance imaging (MRI) will detect these labeled stem cells, and it will be helpful for follow-up of the patient. ${ }^{[10]}$

Another interesting use of iron nanoparticles is to deliver anti interleukin-1 $\beta$ to the epileptogenic focus in the temporal lobe. This technique will be helpful for MRI diagnosis and therapy of epilepsy. ${ }^{[11]}$

Carbon nanowires and nanotubes are being tried to use in neural repair and regeneration. They have an influence on cellular signal transmission. They are showing promising results in:

1. Neural regeneration and repair

2. Repair of stroke damage

3. Treatment of cancer and brain tumors

4. Improvement of cerebrovascular dysfunction after brain trauma

5. For diagnosis as well as treatment of primary brain tumors

6. Augmentation of neural cell function within the brain. ${ }^{[12]}$

Naturally, it is evident that application of nanotechnology will be a great achievement in the field of neurology. It will help diagnose as well as treat many neurologic conditions. We will wait to enlighten ourselves with further knowledge about this in future.

\section{Financial support and sponsorship}

Nil.

\section{Conflicts of interest}

There are no conflicts of interest.

Adrija Hajra, Dhrubajyoti Bandyopadhyay ${ }^{1}$, Shyamal Kumar Hajra ${ }^{2}$

Department of Internal Medicine, IPGMER, Kolkata, West Bengal, ${ }^{1}$ Department of Accident and Emergency, Lady Hardinge Medical College, New Delhi, ${ }^{2}$ NMB Diagnostic Centre, Serampore, Hooghly, Kolkata, West Bengal, India

Address for correspondence: Dr. Adrija Hajra, 38/A/2, SB Ghosh Lane, Serampore, Hooghly, Kolkata - 712 202, West Bengal, India. E-mail: adrija847@gmail.com

\section{References}

1. Binyamin O, Larush L, Frid K, Keller G, Friedman-Levi Y, Ovadia H, et al. Treatment of a multiple sclerosis animal model by a novel nanodrop formulation of a natural antioxidant. Int J Nanomedicine 2015;10:7165-74.

2. Liu J, He Y, Zhang J, Li J, Yu X, Cao Z, et al. Functionalized nanocarrier combined seizure-specific vector with P-glycoprotein modulation property for antiepileptic drug delivery. Biomaterials 2016;74:64-76.

3. Portnoy E, Polyak B, Inbar D, Kenan G, Rai A, Wehrli SL, et al. Tracking inflammation in the epileptic rat brain by bi-functional fluorescent and magnetic nanoparticles. Nanomedicine 2016. pii: S1549-963400088-5.

4. Lim K, Kim SY, Lee B, Segarra C, Kang S, Ju Y, et al. Magnetic microparticle-based multimer detection system for the detection of prion oligomers in sheep. Int J Nanomedicine 2015;10:241-50.

5. Chen PJ, Kang YD, Lin CH, Chen SY, Hsieh CH, Chen YY, et al. Multitheragnostic multi-GNRs crystal-seeded magnetic nanoseaurchin for enhanced in vivo mesenchymal-stem-cell homing, multimodal imaging, and stroke therapy. Adv Mater 2015;27:6488-95.

6. Han L, Kong DK, Zheng MQ, Murikinati S, Ma C, Yuan P, et al. Increased nanoparticle delivery to brain tumors by autocatalytic priming for improved treatment and imaging. ACS Nano 2016;10:4209-18.

7. Han L, Cai Q, Tian D, Kong DK, Gou X, Chen Z, et al. Targeted drug delivery to ischemic stroke via chlorotoxin-anchored, lexiscan-loaded nanoparticles. Nanomedicine 2016. pii: S1549-963430018-1.

8. Choonara YE, Kumar P, Modi G, Pillay V. Improving drug delivery technology for treating neurodegenerative diseases. Expert Opin Drug Deliv 2016:1-15. DOI:10.1517/17425247.2016.1162152

9. Kotb S, Detappe A, Lux F, Appaix F, Barbier EL, Tran VL, et al. Gadolinium-based nanoparticles and radiation therapy for multiple brain melanoma metastases: Proof of concept before phase I trial. Theranostics 2016;6:418-27.

10. Ramos-Gómez M, Martínez-Serrano A. Tracking of iron-labeled human neural stem cells by magnetic resonance imaging in cell replacement therapy for Parkinson's disease. Neural Regen Res 2016;11:49-52.

11. Fu T, Kong Q, Sheng H, Gao L. Value of functionalized superparamagnetic iron oxide nanoparticles in the diagnosis and treatment of acute temporal lobe epilepsy on MRI. Neural Plast 2016;2016:2412958.

12. Vidu R, Rahman M, Mahmoudi M, Enachescu M, Poteca TD, Opris I. Nanostructures: A platform for brain repair and augmentation. Front Syst Neurosci 2014;8:91.

This is an open access article distributed under the terms of the Creative Commons Attribution-NonCommercial-ShareAlike 3.0 License, which allows others to remix, tweak, and build upon the work non-commercially, as long as the author is credited and the new creations are licensed under the identical terms.

\begin{tabular}{|l|l|}
\hline \multicolumn{2}{|c|}{ Access this article online } \\
\hline Quick Response Code: & Website: \\
\hline & www.ruralneuropractice.com \\
\cline { 2 - 2 } & \\
\hline
\end{tabular}

How to cite this article: Hajra A, Bandyopadhyay D, Hajra SK. Future in neuromedicine: Nanotechnology. J Neurosci Rural Pract 2016;7:613-4. 